\title{
Engine Icing Modeling and Simulation (Part 2): Performance Simulation of Engine Rollback Phenomena
}

Ryan D. May

ASRC Aerospace Corporation, Cleveland, Ohio

Ten-Huei Guo, Joseph P. Veres, and Philip C.E. Jorgenson

Glenn Research Center, Cleveland, Ohio 


\section{NASA STI Program . . . in Profile}

Since its founding, NASA has been dedicated to the advancement of aeronautics and space science. The NASA Scientific and Technical Information (STI) program plays a key part in helping NASA maintain this important role.

The NASA STI Program operates under the auspices of the Agency Chief Information Officer. It collects, organizes, provides for archiving, and disseminates NASA's STI. The NASA STI program provides access to the NASA Aeronautics and Space Database and its public interface, the NASA Technical Reports Server, thus providing one of the largest collections of aeronautical and space science STI in the world. Results are published in both non-NASA channels and by NASA in the NASA STI Report Series, which includes the following report types:

- TECHNICAL PUBLICATION. Reports of completed research or a major significant phase of research that present the results of NASA programs and include extensive data or theoretical analysis. Includes compilations of significant scientific and technical data and information deemed to be of continuing reference value. NASA counterpart of peer-reviewed formal professional papers but has less stringent limitations on manuscript length and extent of graphic presentations.

- TECHNICAL MEMORANDUM. Scientific and technical findings that are preliminary or of specialized interest, e.g., quick release reports, working papers, and bibliographies that contain minimal annotation. Does not contain extensive analysis.

- CONTRACTOR REPORT. Scientific and technical findings by NASA-sponsored contractors and grantees.
- CONFERENCE PUBLICATION. Collected papers from scientific and technical conferences, symposia, seminars, or other meetings sponsored or cosponsored by NASA.

- SPECIAL PUBLICATION. Scientific, technical, or historical information from NASA programs, projects, and missions, often concerned with subjects having substantial public interest.

- TECHNICAL TRANSLATION. Englishlanguage translations of foreign scientific and technical material pertinent to NASA's mission.

Specialized services also include creating custom thesauri, building customized databases, organizing and publishing research results.

For more information about the NASA STI program, see the following:

- Access the NASA STI program home page at http://www.sti.nasa.gov

- E-mail your question via the Internet to help@ sti.nasa.gov

- Fax your question to the NASA STI Help Desk at $443-757-5803$

- Telephone the NASA STI Help Desk at 443-757-5802

- Write to: NASA Center for AeroSpace Information (CASI) 7115 Standard Drive Hanover, MD 21076-1320 


\section{Engine Icing Modeling and Simulation (Part 2): Performance Simulation of Engine Rollback Phenomena}

Ryan D. May

ASRC Aerospace Corporation, Cleveland, Ohio

Ten-Huei Guo, Joseph P. Veres, and Philip C.E. Jorgenson

Glenn Research Center, Cleveland, Ohio

Prepared for the

International Conference on Aircraft and Engine Icing and Ground Deicing sponsored by the SAE International

Chicago, Illinois, June 13-17, 2011

National Aeronautics and

Space Administration

Glenn Research Center

Cleveland, Ohio 44135 


\section{Acknowledgments}

The authors would like to thank Sanjay Garg and James Heidmann of the NASA Glenn Research Center for their support and the Aviation Safety Program’s Vehicle Systems Safety Technologies program for the funding to do this research.

Trade names and trademarks are used in this report for identification only. Their usage does not constitute an official endorsement, either expressed or implied, by the National Aeronautics and Space Administration.

Level of Review: This material has been technically reviewed by technical management.

Available from

NASA Center for Aerospace Information 7115 Standard Drive

Hanover, MD 21076-1320
National Technical Information Service 5301 Shawnee Road Alexandria, VA 22312

Available electronically at http://www.sti.nasa.gov 


\title{
Engine Icing Modeling and Simulation (Part 2): Performance Simulation of Engine Rollback Phenomena
}

\author{
Ryan D. May \\ ASRC Aerospace Corporation \\ Cleveland, Ohio 44135 \\ Ten-Huei Guo, Joseph P. Veres, and Philip C.E. Jorgenson \\ National Aeronautics and Space Administration \\ Glenn Research Center \\ Cleveland, Ohio 44135
}

\begin{abstract}
Ice buildup in the compressor section of a commercial aircraft gas turbine engine can cause a number of engine failures. One of these failure modes is known as engine rollback: an uncommanded decrease in thrust accompanied by a decrease in fan speed and an increase in turbine temperature. This paper describes the development of a model which simulates the system level impact of engine icing using the Commercial Modular Aero-Propulsion System Simulation 40k (C-MAPSS40k). When an ice blockage is added to C-MAPSS40k, the control system responds in a manner similar to that of an actual engine, and, in cases with severe blockage, an engine rollback is observed. Using this capability to simulate engine rollback, a proof-of-concept detection scheme is developed and tested using only typical engine sensors. This paper concludes that the engine control system's limit protection is the proximate cause of iced engine rollback and that the controller can detect the buildup of ice particles in the compressor section. This work serves as a feasibility study for continued research into the detection and mitigation of engine rollback using the propulsion control system.
\end{abstract}

\subsection{Introduction}

Ice crystals have been found to accrete in the core of commercial turbofan engines at locations where the temperatures are initially above freezing (Ref. 1). This icing can lead to many different engine failure modes, including compressor surge/stall, combustor flameout, compressor blade damage, and engine rollback. While ice shedding is the direct cause of most of these failures (Ref. 2), the accretion of ice may also be responsible for engine power loss. It was determined that in turbofan engines the rollback event is caused by ice buildup in the engine's low pressure compressor; additionally, the potential for ice accretion exists in the first few stages of the high pressure compressor (Ref. 1). Engine rollback has been defined in Reference 1 as an uncommanded thrust reduction that is accompanied by a gradual decrease in fan shaft speed and an increase in Turbine Gas Temperature (TGT). Further, the engine does not respond to pilot commanded thrust increases. In cases where the engine was then shut-down, it was capable of being restarted after the aircraft descended to an altitude of approximately $10,000 \mathrm{ft}$. Engines that were not shut down began to operate normally at roughly the same altitude. This return to normal operation is possible at lower altitudes due to the increased air temperatures causing the ice to melt or shed.

Since the identification of engine icing, over 100 engine power loss events have been recorded in both large transport airplanes as well as small jet aircraft (Ref. 2). To date, most of the work has focused on identifying the mechanism by which ice crystal accretion occurs and determining the environmental conditions in which engine icing is likely (Refs. 1 to 4 ). The general approach taken by the community has been to design an engine that does not accumulate ice in these conditions or to avoid getting the airplane into a flight condition with High Ice Water Content (HIWC). However, complete avoidance is not possible and replacing all currently operating engines is not feasible. To this end, improving the capability of a current engine to safely handle these icing scenarios is critically important.

The authors believe that an engine control system, working either with its own information or in coordination with airframe sensors, can detect the accretion of ice in the engine core prior to an engine rollback and then alter the control logic to mitigate the impact of the blockage. To develop these ideas further, it is critical to have an engine simulation environment in which one can simulate the impact of ice accretion in the engine core and test potential detection and mitigation strategies.

The key features that an engine simulation must have to be useful in this effort are: (1) highly accurate compressor surge margins, (2) an engine controller that is representative of that found on modern commercial gas turbine engines, and 3) a modular nature to allow modification of engine components and the engine control law as necessary. For these reasons the Commercial Modular Aero-Propulsion System Simulation 40k (C-MAPSS40k) was selected for use in this investigation. C-MAPSS40k is a publicly available, MATLAB/Simulink (The Mathworks, Inc.) based simulation of a generic 40,000 lbf thrust class, twin spool, high bypass, commercial aircraft engine (Ref. 5). The simulation includes a realistic engine control system that exceeds applicable sections of the 
US Code of Federal Regulations (14 CFR 33) while preserving the safety and operability of the engine (Ref. 6). As described in Reference 6, the control system is comprised of a Power Management system and Protection Logic system. The Power Management system is responsible for converting the pilot's commanded thrust level into a fuel flow command to the engine and then maintaining that thrust level. The Power Management system maintains thrust by feeding back either the Engine Pressure Ratio (EPR) or the fan speed; for this paper, the engine is controlled based on EPR. While all of the simulation results shown in this paper are from an EPR controlled engine, the same conclusions are drawn for a fan speed controlled engine. The Protection Logic system is in place specifically to ensure that the engine always operates in a safe state. There is logic in place to prevent combustor over-pressurization, combustor blowout, compressor surge, and fan and core shaft over-speed conditions. By modifying the C-MAPSS40k simulation to include ice blockage, we can observe the response of the nominal control system and then work to develop control law modifications to detect and mitigate the effects of the ice accretion.

Part I of this work (Ref. 7) has focused on developing models of engine icing. In Part II, the study takes a systems level look at the effect of ice accretion on engine performance. In Section 2.0 we will look at how to introduce ice accretion into the C-MAPSS40k simulation. A brief discussion of current engine control systems is given in Section 3.0. Simulation results highlighting the role of the engine controller during engine ice accretion are presented in Section 4.0. Detection of ice accretion using existing engine sensors is discussed in Section 5.0 followed by conclusions and future work in Section 6.0.

\subsection{Definitions/Abbreviations}

\section{C-MAPSS40k The Commercial Modular Aero- Propulsion System Simulation 40k \\ EGT Exhaust Gas Temperature (deg R) \\ EPR Engine Pressure Ratio}

Fnet $\quad$ Net Thrust (lbf)

HIWC High Ice Water Content

HPC High Pressure Compressor

ISA International Standard Atmosphere

LPC Low Pressure Compressor

PLA Power Lever Angle

TGT Turbine Gas Temperature

Wf Mass rate of fuel $(\mathrm{lbm} / \mathrm{s})$

\subsection{Modeling Engine Icing}

C-MAPSS40k is an axial-symmetric, lumped volume model where each of the engine components has an input and output with the relation governed by maps. The thermodynamic models in the simulation are not detailed enough to model the accretion of ice crystals on the compressor stator vanes. Thus in order to simulate the ice buildup and the associated compressor flow changes, the compressor map itself must be modified. Part I of this research effort (Ref. 7) conducted a detailed study of the thermodynamic events associated with ice crystal accretion leading to conclusions about where and under what conditions ice buildup in the Low Pressure Compressor (LPC) occurs. Based on this data, mean-line flow analysis software (COMDES) (Ref. 8) was used to construct blocked LPC maps for small operating regions.

An LPC map which models the effects of a 20 percent blockage of the first stator was expanded to cover the entire operating envelope to be included in C-MAPSS40k. A comparison of the nominal LPC map and the 20 percent blocked map is shown in Figure 1. From an engine level perspective there are a number of important differences between the two maps: (1) there is a large decrease in the LPC surge line and (2) as the shaft speed increases the speed lines get dramatically steeper. The reduction in surge line means that the blocked compressor will be much more likely to surge than an unblocked compressor and the nominal engine controller limits, which are designed to prevent LPC

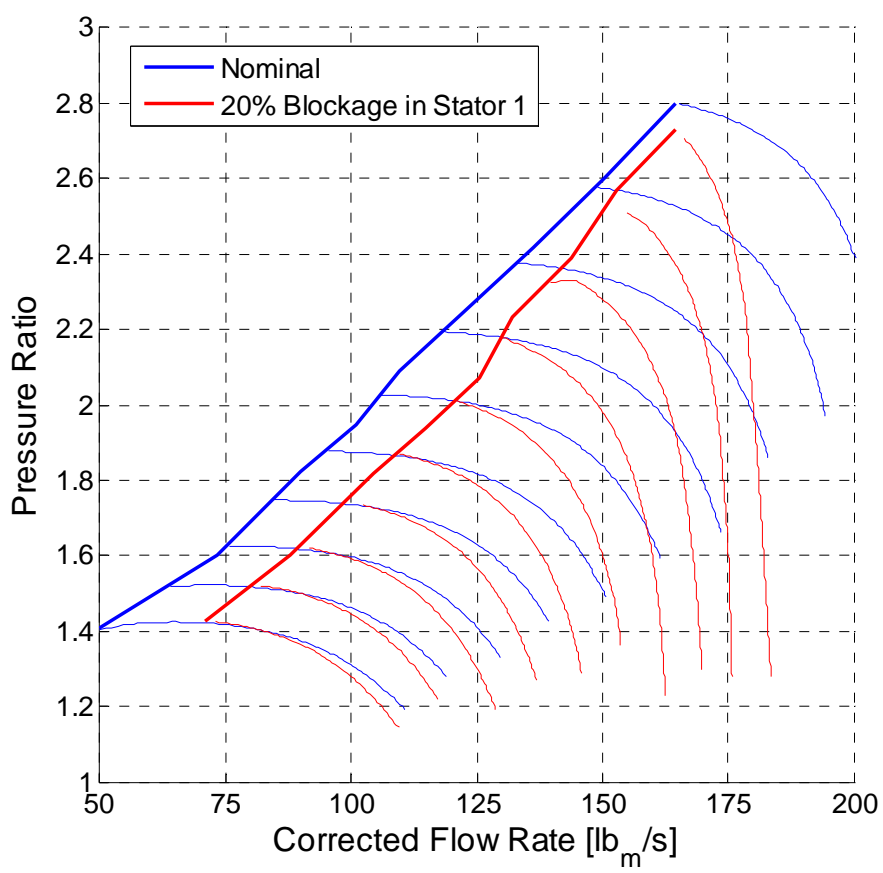

Figure 1.-Constant corrected speed lines and surge lines of the nominal LPC map (blue) compared with those of the LPC map with a 20 percent blockage in Stator 1 (red). 
surge during decelerations, may not be as effective. The large shift of the speed lines to the left means that at a given fan shaft speed much less air will move through the compressor for a given pressure ratio. By decreasing the core mass flow rate, the blockage will force the engine controller to increase the fuel flow rate into the combustor to generate enough power to produce the desired EPR setpoint.

While it is possible to replace the LPC map used in C-MAPSS40k with the blocked map, running at a steady state blockage is not the most important situation. Of greater interest is the transient impact of ice accretion in the compressor. In order to simulate the accretion the LPC must move from using the nominal map to the blocked map. While the buildup does not have a linear impact on the compressor map, we will initially make this assumption as additional blocked compressor maps are not yet available. By beginning the simulation on the nominal LPC map and then slowly transitioning to the 20 percent blockage map, we can roughly simulate the accretion of ice inside the LPC.

Previous research efforts have found that ice crystal accretion in commercial aircraft engines most commonly occurs at altitudes from 11,500 to $39,000 \mathrm{ft}$ with a median of $25,800 \mathrm{ft}$ and with the ambient air significantly warmer than standard atmosphere (ISA), most frequently ISA+6 and greater (Ref. 1). Therefore, our simulations will occur at a cruise condition: 25,000 ft altitude, Mach 0.75, ISA+10, and a cruise throttle setting. Figure 2 shows the engine outputs at this flight condition for a $10 \mathrm{sec}$ transition from the nominal LPC map to the 20 percent map starting at 20 sec into the simulation. The choice of $10 \mathrm{sec}$ was made to reduce simulation time, the actual growth rate of the ice blockage is unknown. The simulation results confirm the earlier stated expectations of the interaction between the ice accretion and the engine controller. As the mass flow rate through the LPC decreases due to the blockage, the controller commands a fuel flow rate $\left(\mathrm{W}_{\mathrm{f}}\right)$ increase in order to maintain a constant EPR. The increase in fuel flow rate results in an increase in core shaft speed $\left(\mathrm{N}_{\mathrm{c}}\right)$ and fan shaft speed $\left(\mathrm{N}_{\mathrm{f}}\right)$ due to increased power available at the turbines. Since most of the thrust of a high-bypass gas turbine engine is generated by the movement of air through the bypass duct, the increase in fan speed results in more air moving through the bypass duct and thus higher thrust production $\left(\mathrm{F}_{\text {net }}\right)$.

While the results meet expectations, there is no evidence of an engine rollback event. In fact, using this modeling approach there is no evidence of a thrust decrease until the test is conducted at the highest altitude, speed, and thrust level the engine is capable of. Thus in order to obtain a decrease in thrust the LPC map must be extended further than 20 percent blockage. However, as we do not have a higher blockage map, we must find an alternate method of simulating this behavior.

By changing the compressor map, the pressure ratio across the LPC changes as well as the mass flow rate through the compressor. When using the 20 percent blockage map, a 12 percent steady-state reduction in LPC output pressure
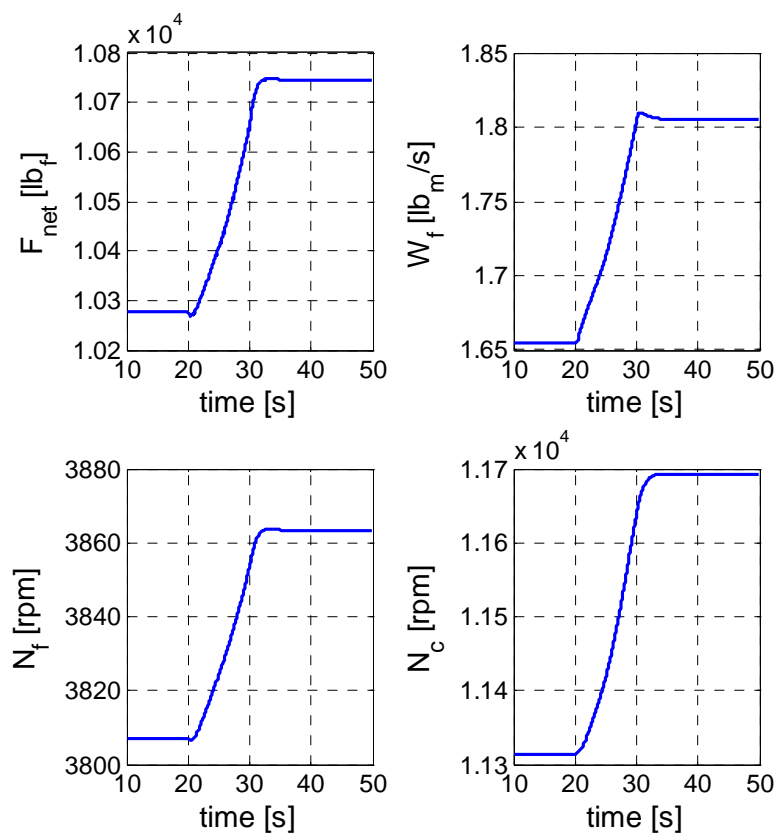

Figure 2.-Engine outputs (thrust, fuel flow rate, fan speed, and core speed) for a $10 \mathrm{sec}$ transition from nominal LPC map to 20 percent blocked LPC map at cruise $(25,000 \mathrm{ft}$, Mach 0.75, ISA+10) starting at $t=20 \mathrm{sec}$.

occurs. Using this knowledge as a starting point, a pressure drop is inserted into the C-MAPSS40k LPC. This pressure drop is then linearly increased during the simulation to simulate the accretion of the ice crystals. Comparing the engine outputs for the compressor map transition and a transition from 0 percent pressure drop to 12 percent pressure drop shows similar behavior (see Fig. 3). As expected the steady state EPR values are identical for both cases. However, the modeling differences result in a 2.3 percent difference in fuel flow rate. While some of the engine outputs appear to have a large deviation, the fan speed error is only 1.0 percent and there is a 2.4 percent difference in net thrust. The core speed matches extremely well and the turbine gas temperature error is 1.6 percent. While this match is not perfect, it does result in the same general behavior as using the blocked compressor maps. Similar results are found if a flow rate blockage is used instead of a pressure drop but with slightly higher steady-state error.

In lieu of additional blocked compressor maps, this pressure drop approximation can allow us to extend our study to higher blockage levels. While no longer directly connected to a blockage percentage, the pressure drop can be increased until an engine rollback occurs as shown in Figure 4. When the pressure drop is increased to 23 percent the behavior is much like that of the 12 percent pressure drop, except that there is a slight decrease in thrust shortly after the pressure has stabilized. However, once the pressure drop reaches 26 percent (as shown in Fig. 4) there is a large decrease in engine thrust and fan speed along with a large spike in TGTan engine rollback has occurred. 

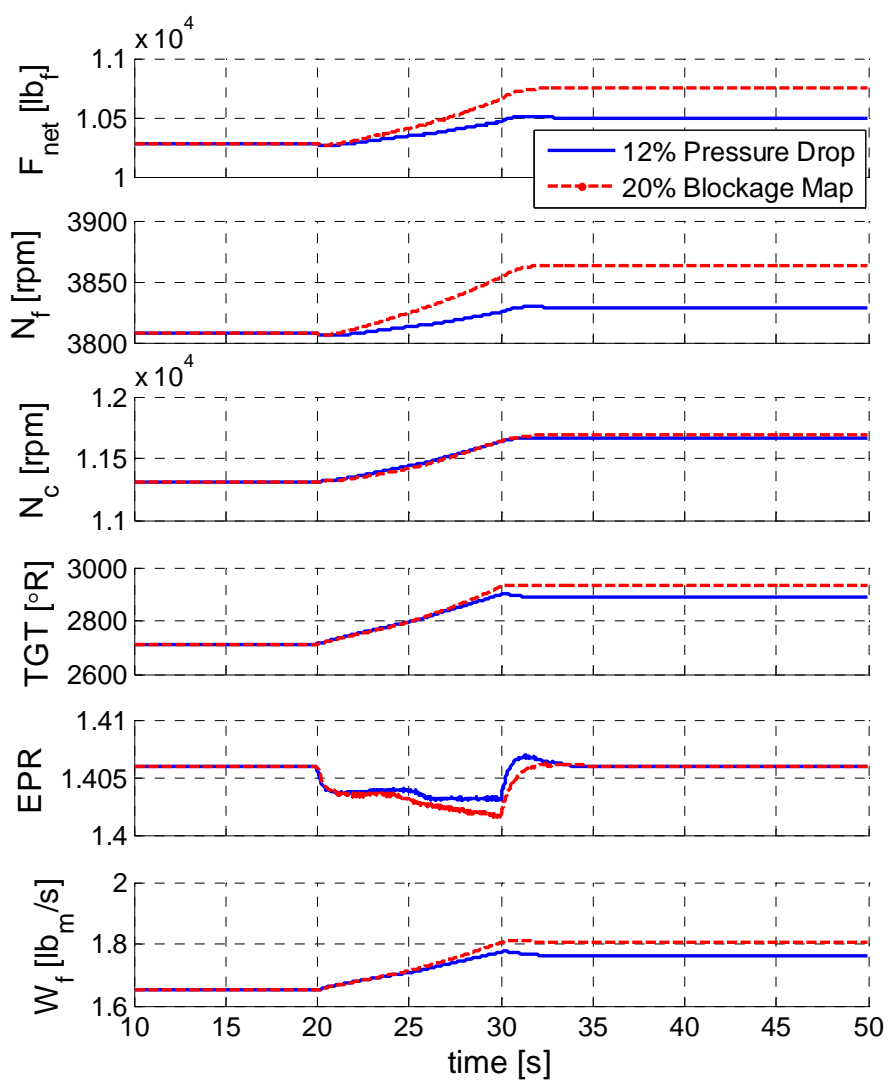

Figure 3.-Engine outputs comparing a $10 \mathrm{sec}$ transition from nominal LPC map to 20 percent blocked LPC map (dashed) to a 0 to 12 percent pressure drop across the LPC (solid) at cruise $(25,000 \mathrm{ft}$, Mach 0.75 , ISA+10) starting at $t=20 \mathrm{sec}$.

The other aspect of engine rollback is the fact that a throttle increase will not result in a thrust increase. To verify that this holds true in C-MAPSS40k, the same 26 percent pressure drop used above is again used with a throttle increase from cruise to maximum power at $40 \mathrm{sec}$. The results shown in Figure 5 show the same thrust decrease and then no thrust response to the throttle increase. Examining the fuel flow rate plot it can be seen that until approximately $32 \mathrm{sec}$ the actual fuel flow rate is nearly the same as that desired by the EPR controller, however after that point they diverge. A change in desired fuel flow rate can be seen when the burst occurs with no corresponding change in the actual fuel flow rate. If we then look at the actual and desired EPR, we see that during the pressure drop transition the actual EPR deviates from the desired by ever increasing amounts until the rollback occurs and the EPR sharply decreases. Again, the desired EPR increases with the throttle increase, but the actual EPR does not change. The pilot is no longer able to command thrust increases due to the engine rollback.

It is apparent that the engine controller is preventing the engine from reaching the desired EPR. In order to determine what aspect of the control system is limiting the fuel flow rate, we start with an overview of a nominal engine controller and the C-MAPSS40k controller in specific.
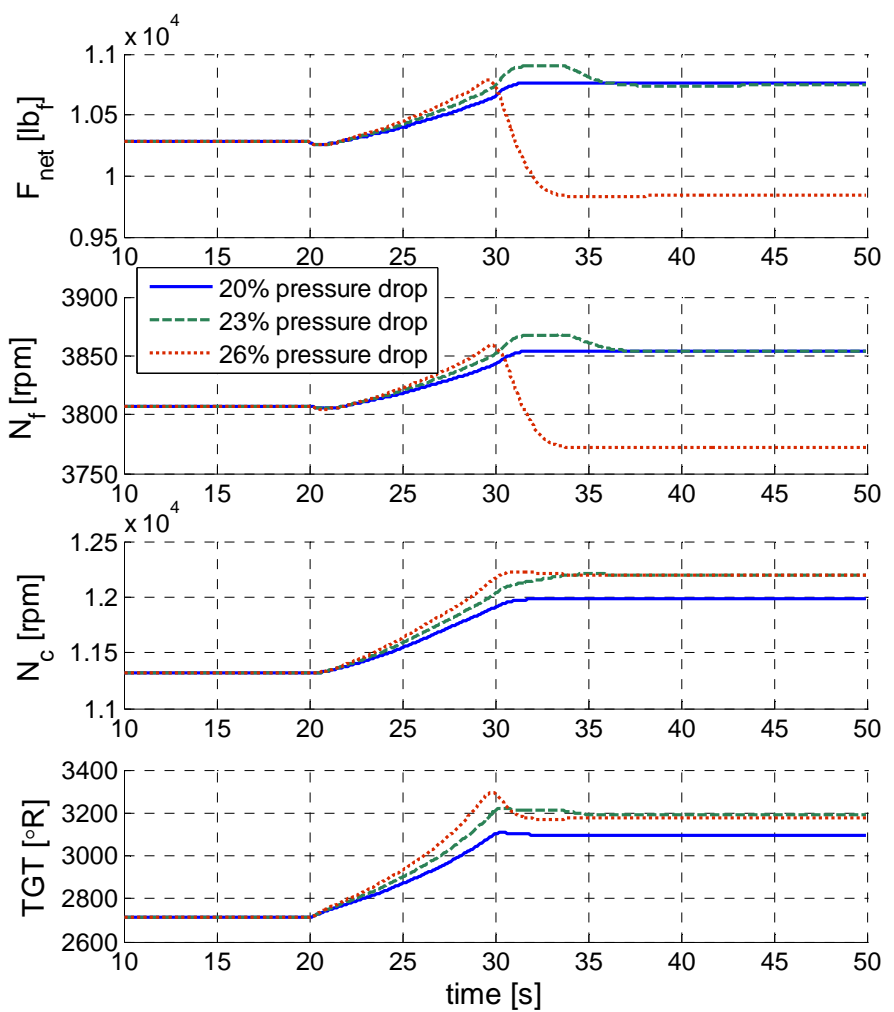

Figure 4.-Engine outputs comparing a $10 \mathrm{sec}$ transition from 0 to 20 percent (solid), 23 percent (dashed), and 26 percent (dotted) pressure drop across the LPC at cruise $(25,000 \mathrm{ft}$, Mach $0.75, \mathrm{ISA}+10)$ starting at $t=20 \mathrm{sec}$. Engine rollback occurs at approximately $t=30 \mathrm{sec}$.
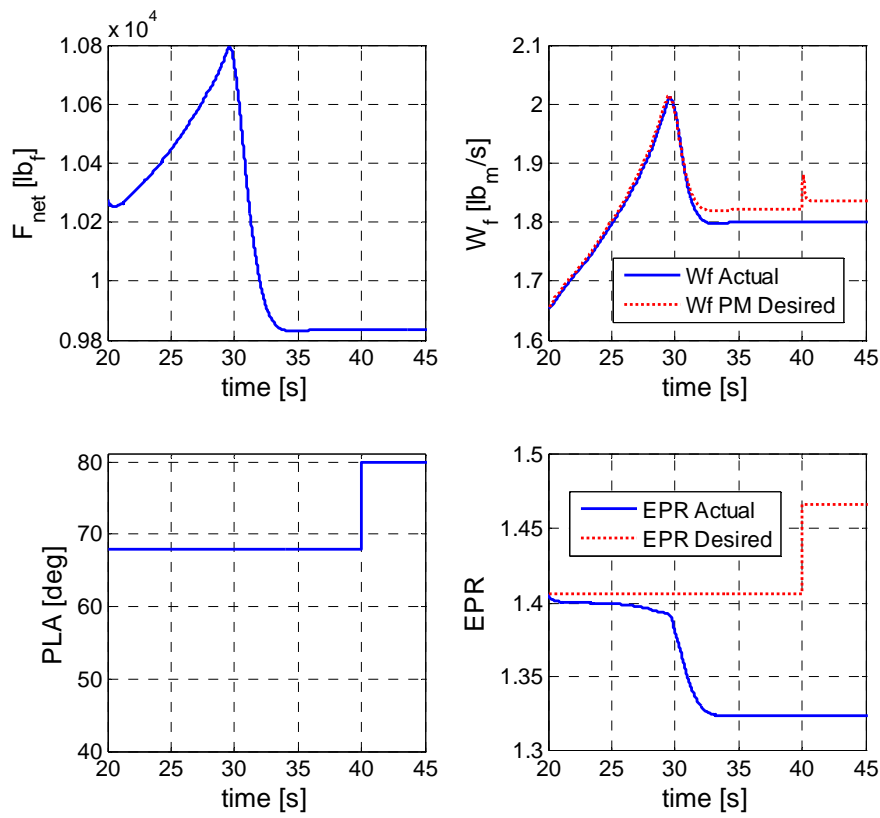

Figure 5.-Engine and controller outputs for a $10 \mathrm{sec}$ transition from 0 to 26 percent pressure drop across the LPC at cruise $(25,000 \mathrm{ft}$, Mach 0.75 , ISA +10$)$ starting at $t=20 \mathrm{sec}$. Engine rollback occurs at approximately $t=30 \mathrm{sec}$, followed by a PLA burst from $68^{\circ}$ to $80^{\circ}$ at $t=40 \mathrm{sec}$. 


\subsection{Engine Control Systems}

A typical commercial aircraft engine control system is comprised of two main components as shown in Figure 6 (Ref. 6). The first is the Power Management controller, which is designed to regulate the engine performance at a specified power level. Ideally, the pilot would be able to command a thrust level; however, thrust is not measurable while in flight and so alternate parameters are used-typically either fan speed or engine pressure ratio (EPR). Each of these signals is directly related to the thrust output and can serve as an indicator of the thrust level. The pilot's throttle position is converted to a fan speed or EPR setpoint and maintained there with a proportional-integral controller. The throttle command used in C-MAPSS40k is referred to as the power lever angle (PLA) which ranges from a flight idle setting of $40^{\circ}$ to maximum power at $80^{\circ}$.

The other component of the engine control system is the Protection Logic whose purpose is to ensure the safe operation of the engine. As a primary concern, the engine needs to be operated in such a way that no component will fail. This means protecting components like turbine disks, rotor blades, and combustor casing from exceeding their acceptable stress levels. To ensure this, engine pressures and shaft speeds are monitored and prevented from exceeding a maximum limit. The second aspect to "safe operation" is the prevention of compressor surge. Surge occurs when a compressor can no longer maintain the necessary pressure ratio, resulting in a reversal of flow through the engine, a sudden loss of engine thrust, and potentially severe damage to engine components. The High Pressure Compressor (HPC) is more likely to surge during throttle increases while the Low Pressure Compressor (LPC) is more likely to surge during a throttle decrease. Unfortunately, there is currently no means to directly measure how close the engine is to surging; however, there are a number of indirect means to prevent compressor surge (Ref. 9). In C-MAPSS40k, HPC surge is prevented by the use of an acceleration limit. This limit restricts the fuel flow rate in order to prevent the core shaft from accelerating faster than a preset limit based on the current core speed. The faster the core shaft is spinning the more acceleration is allowed. LPC surge on deceleration is prevented by ensuring that the fuel flow rate to the engine does not decrease too quickly. The specific details of the protection logic implemented in the C-MAPSS40k engine controller can be found in Reference 6 .

A challenging aspect of engine control and diagnostics is the limited number of sensors installed in the engine. For example, there are no temperature sensors in the turbine section of the engine due to the extremely high temperatures. Thus instead of measuring TGT, a sensor is installed which measures Exhaust Gas Temperature (EGT). The EGT will track the TGT but will be delayed and the magnitude of temperature swings will be smaller. In addition to the EGT sensor, C-MAPSS40k is equipped with fan speed, core speed, four pressure, and three other temperature sensors (Ref. 5).

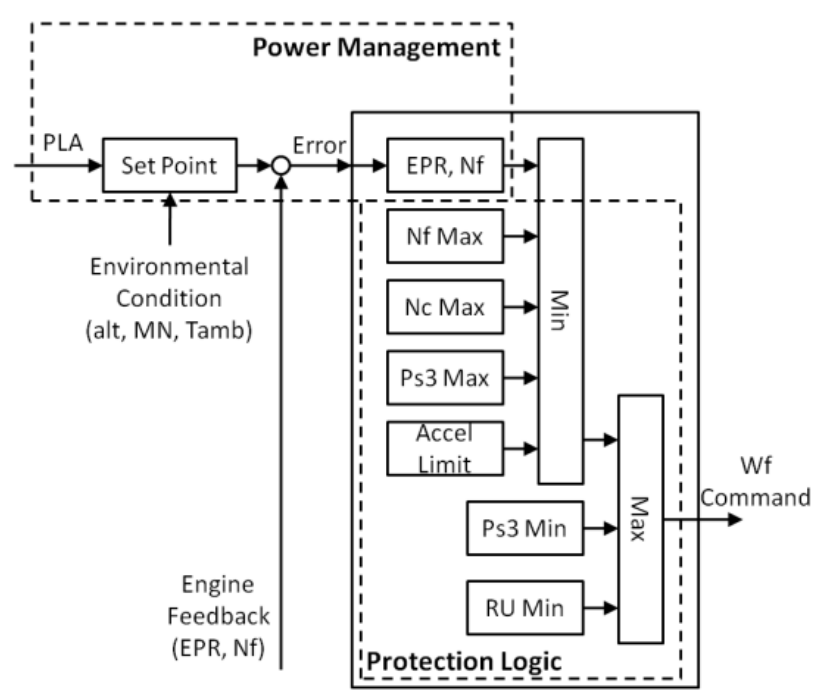

Figure 6.-Diagram of the C-MAPSS40k engine control system with throttle (PLA) input and fuel flow rate command output. The Power Management and Protection Logic subsystems are highlighted.

Further complicating the lack of sensors is the lack of actuators available to modify the engine behavior. C-MAPSS40k is equipped with three actuators: a fuel metering valve, a set of variable stator vanes (inlet guide vanes) at the entrance to the HPC, and a variable sized bleed valve between the two compressors. Under nominal conditions, the fuel flow rate is actively controlled while the stator vanes and bleed valve are scheduled based on sensed engine conditions. However, in abnormal situations it is possible to move the actuators off of their nominal schedule to alter engine behavior.

\subsection{Engine Control During Icing}

It is clear that the Protection Logic component of the engine control system is preventing the fuel flow rate from being high enough to achieve the target EPR during engine icing. To highlight this fact a test comparing the effect of disabling the control limiters is shown in Figure 7. The maximum core speed limit $(12,200 \mathrm{rpm})$ is shown on the core speed plot and it is apparent that this limit prevents the fuel flow rate from increasing and driving the core speed over its limit. When the limits are removed, the engine is able to reach a new steadystate point with the ice accretion (albeit at a significantly higher thrust level) and the throttle command at $40 \mathrm{sec}$ executes as desired.

Not every engine control system has the same limits, but the general reaction across all of them will be similar when faced with engine ice accretion. The ice buildup causes a decrease in engine output (either fan speed or EPR) and so the fuel flow rate is increased to compensate. At some point the controller hits a maximum safety limit; in the case of C-MAPSS40k that is the core shaft speed limit, but in other cases it may be a maximum fuel flow rate limit (Ref. 10), temperature, or fan 

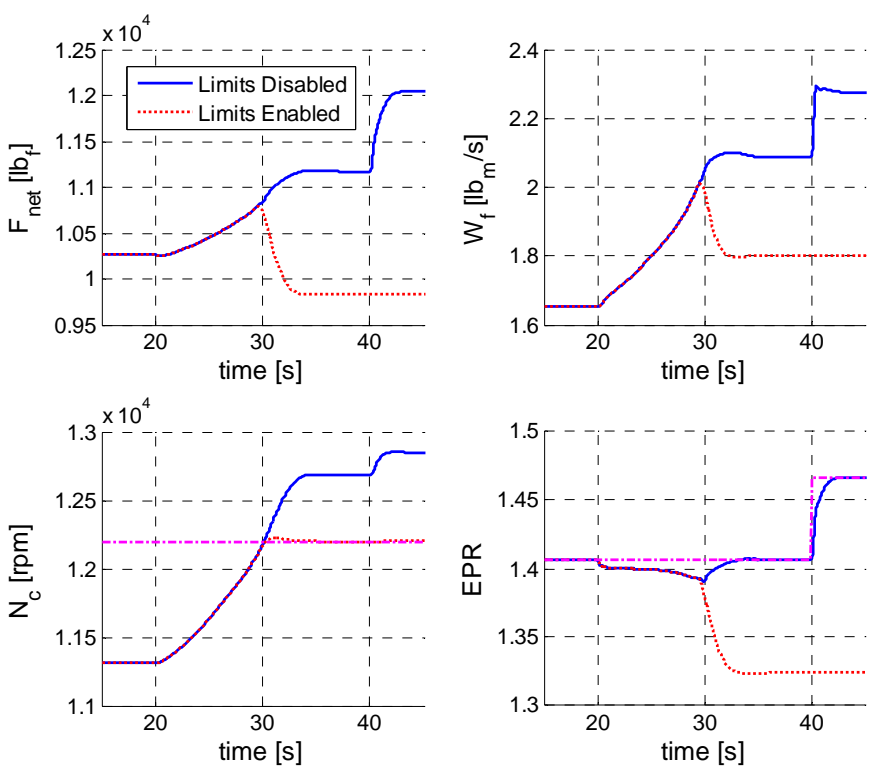

Figure 7.-Engine and controller outputs for a $10 \mathrm{sec}$ transition from 0 to 26 percent pressure drop across the LPC at cruise $(25,000 \mathrm{ft}$, Mach $0.75, \mathrm{ISA}+10)$ starting at $t=20 \mathrm{sec}$. Engine rollback occurs at approximately $t=30 \mathrm{sec}$, followed by a PLA burst from $68^{\circ}$ to $80^{\circ}$ at $t=40 \mathrm{sec}$ with controller limits disabled (solid) and limits enabled (dotted). The dash-dot line on the core speed plot is the nominal core speed limit and the dash-dot line on the EPR plot is the EPR setpoint.

speed. Once the limit is hit, the controller switches to a more conservative approach; for C-MAPSS40k this meant controlling to maintain maximum core speed, other cases may switch to an idle setpoint.

While it is enticing to simply remove (or extend) the limits to prevent the rollback for occurring, this is not possible as the safety limits are actually being violated; changing the limits would expose the engine to excessive risk of failure. Thus after detecting the accretion of ice the engine operating state must change to avoid rollback while allowing for safe engine operation. If a precise knowledge of the health of the engine components is available then in some cases the limits can be extended while accepting minimal risk (Ref. 11), however these techniques are only in early developmental stages.

\subsection{Detection of Engine Icing}

Early detection of engine ice accretion is critical to enable the modification of engine operation to mitigate the impact of the icing and prevent rollback. As mentioned earlier, there are a limited number of engine sensors available for use in the detection process. C-MAPSS40k has ten sensors, more than typically found on a commercial aircraft engine. In C-MAPSS40k, each sensor is modeled as a first order system and zero-mean Gaussian white noise can be added. Adding typical noise (standard deviation of speed, pressure, and temperature sensors are $0.25,0.50$, and 0.75 percent of trim,
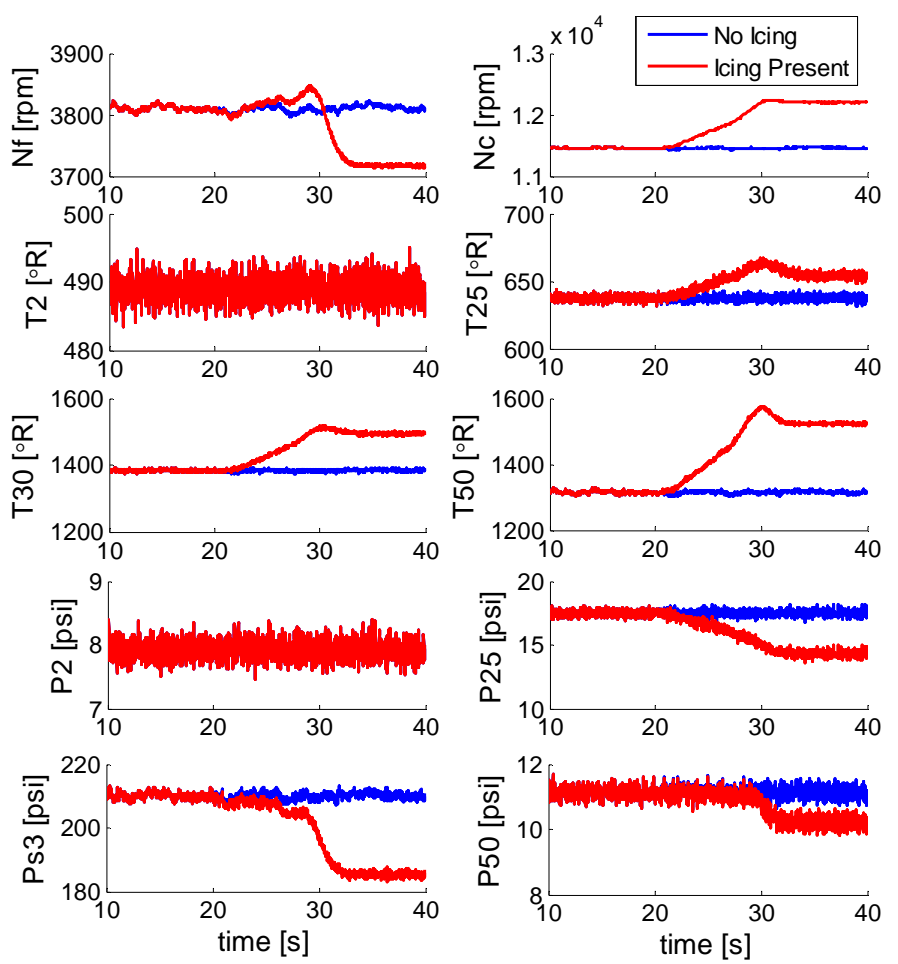

Figure 8.-Noisy sensor outputs for a nominal flight (blue) and a flight with engine icing (red) $-10 \mathrm{sec}$ transition from 0 to 26 percent pressure drop across the LPC at cruise $(25,000 \mathrm{ft}$, Mach 0.75, ISA+10).

respectively) and comparing a case with no icing present to a case with a transition from no pressure drop at $t=20 \mathrm{sec}$ to a 26 percent pressure drop at $t=30 \mathrm{sec}$, the output of the full engine sensor suite is shown in Figure 8. This data indicates that a signature of engine icing in progress may be the increase in core speed and all temperatures while all inputs $\left(P_{2}, T_{2}\right.$, and throttle) are level.

Because the inlet pressure and temperature change with altitude and speed (as well as atmospheric disturbances), they will rarely be constant, it would be better to filter the data and then look at the first derivatives. Then a simple threshold can be applied to detect the accretion of engine ice. While this is a very simplistic approach, it serves as an effective baseline against which to compare other detection schemes. Figure 9 shows an example of this detection approach during a $30 \mathrm{sec}$ descent from 25,000 to 22,500 ft and Mach 0.75 to 0.72 . In order to detect the buildup of icing, the derivative of $P_{2}, T_{2}$, and PLA must all be below their specified threshold while $N_{c}$ and $T_{50}$ are above theirs. When this is true, the detection counter is incremented and when false, the counter is reset. Once the detection counter hits a limit then the event is flagged. In this example, the simulated icing begins at $20 \mathrm{sec}$ and rollback occurs at $30 \mathrm{sec}$. Using the thresholds shown (red horizontal lines) the detection algorithm reaches the preset occurrence count 2.755 sec after the ice accretion begins (vertical red line). 

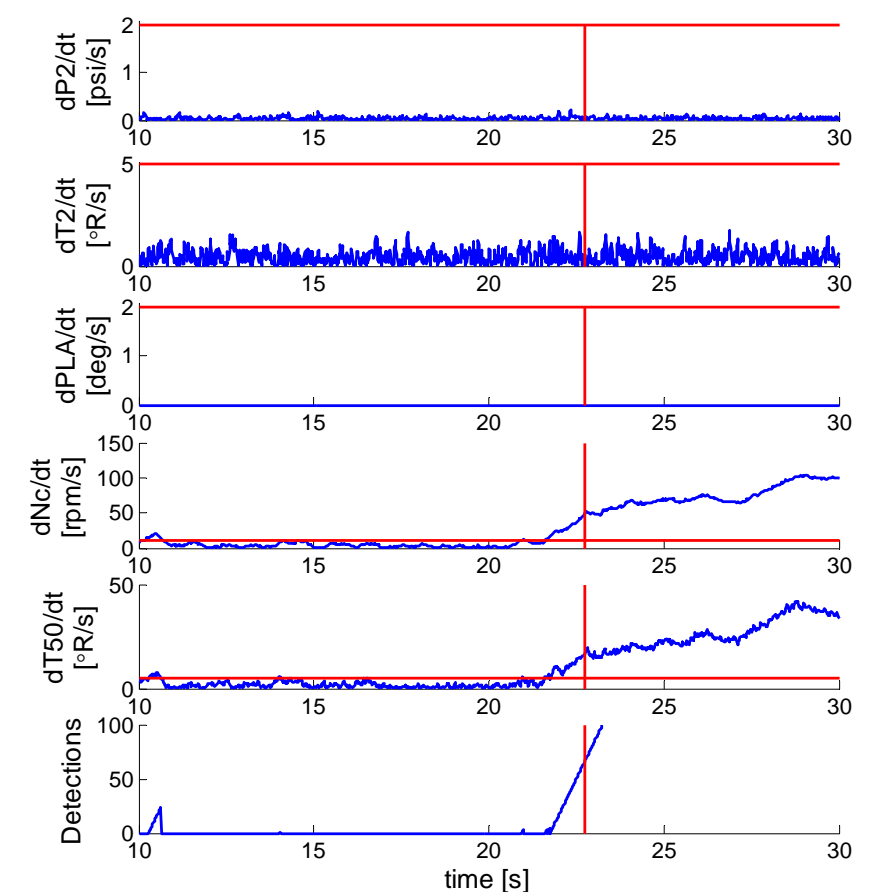

Figure 9.-Detection of engine ice accretion using typical sensor suite during $30 \mathrm{sec}$ descent from 25,000 ft, Mach 0.75 to $22,500 \mathrm{ft}$, Mach 0.72 . The data plotted is the derivative of the filtered sensor output. The horizontal red lines are detection thresholds. Detection occurs $2.755 \mathrm{sec}$ after the onset of icing.

In practice, this detection approach would have a number of problems but it is shown here to highlight the fact that using only the current engine sensor suite, the accretion of ice in the LPC has an identifiable signature that can be used in more complicated fault detection and classification systems (Ref. 12).

\subsection{Conclusions}

It has been found that using C-MAPSS40k, modeling a simple pressure drop across the low pressure compressor allows for the simulation of engine rollback due to engine icing. While this is not an ideal method for simulating the ice blockage it has been shown to produce behavior that is similar to that which results from using a compressor map that has been modified to include the effects of ice blockage. Simulations of engine rollback highlighted the fact that the engine rollback behavior is caused by the engine hitting maximum safety limits and the engine controller switching to a conservative control strategy. Removal of the limits has been shown to be effective at eliminating the engine rollback, but this is not a valid solution due to the increased risk of failure associated with removing (or increasing) the limits. The rapid detection of engine ice accretion should be possible using only the current sensor suite. To actually devise a detection method would require a greater understanding of the rate at which accretion occurs as well as the environmental conditions necessary for icing. Any detection scheme could be integrated with airframe mounted sensing devices to improve detection accuracy and speed.

The work presented in this paper is in the initial stages. To enable future detection and mitigation work it is necessary to improve the modeling approach to use blocked compressor maps. Once the modeling work is completed, detection strategies will be refined and will need to be run against both normal and faulted non-iced engines to determine detection statistics. To enable the creation of mitigation strategies, it is necessary to have a better understanding of the conditions at which ice accretion is possible. Mitigation work will then focus on using the existing actuation to modify the engine operating point to one which prevents further accretion or which sheds the existing buildup. In the long term, a goal is to find engine control techniques that will allow the engine to operate in high ice water content conditions by preventing the accumulation of ice in the compressor.

\section{References}

1. Mason, J.G., Strapp, J.W., Chow, P., "The Ice Particle Threat to Engines in Flight,” AIAA-2006-206-739, 2006.

2. Mason, J., "Current Perspectives on Jet Engine Power Loss in Ice Crystal Conditions: Engine Icing," Presentation at 2008 AIAA Atmospheric and Space Environments, June 23rd, 2009.

3. Lawson, R.P., Angus, L.J., Heymsfield, A.J., "Cloud Particle Measurements in Thunderstorm Anvils and Possible Weather Threat to Aviation," AIAA Journal of Aircraft, Volume 35, Number 1, Pages 113-121, 1998.

4. Strapp, J.W., Ratvasky, T.P., "Jet Engine Power Loss in Ice particle Conditions - The High Ice Water Content (HIWC) Cloud Characterization Study," Presented to the Joint Interagency Weather Research Coordination Meeting, Boulder, CO, March 22-24, 2010.

5. May, R.D., Csank, J., Lavelle, T.M., Litt, J.S., and Guo, T.H., "A High-Fidelity Simulation of a Generic Commercial Aircraft Engine and Controller," AIAA2010-6630, 2010 AIAA Joint Propulsion Conference, Nashville, TN, July, 2010.

6. Csank, J., May, R.D., Litt, J.S., Guo, T.H., “Control Design for a Generic Commercial Aircraft Engine," AIAA-2010-6629, 2010 AIAA Joint Propulsion Conference, Nashville, TN, July, 2010.

7. Jorgenson, C.E., Veres, J.P., Wright, W.B., May, R.D., "Engine Icing Modeling and Simulation (Part 1): Ice Crystal Accretion on Compression System Components and Modeling its Effects on Engine Performance," submitted to SAE Intl Conf on Aircraft and Engine Icing and Ground De-Icing, 2011.

8. Veres, J.P. “Axial and Centrifugal Compressor Mean Line Flow Analysis Method,” AIAA-2009-1641. 
9. Spang III, A.H., and Brown, H., "Control of Jet Engines,” Control Engineering Practice, 8 March 1999, pp. 10431059.

10. Mason, J., “The Ice Crystal Weather Threat to Engines,” Presentation, October 8th, 2007.

11. Csank, J.T., May, R.D., Litt, J.S., Guo, T.H., “The Effect of Modified Control Limits on the Performance of a Generic Commercial Aircraft Engine,” To be published at the 47th AIAA Joint Propulsion Conference \& Exhibit, San Diego, CA, July 31-Aug 3, 2011.
12. Vachtsevanos, G., Lewis, F.L., Roemer, M., Hess, A., Wu, B., "Intelligent Fault Diagnosis and Prognosis for Engineering Systems,” Wiley, 2006. 


\begin{tabular}{|c|c|c|}
\hline \multicolumn{2}{|c|}{ REPORT DOCUMENTATION PAGE } & $\begin{array}{l}\text { Form Approved } \\
\text { OMB No. 0704-0188 }\end{array}$ \\
\hline \multicolumn{3}{|c|}{ 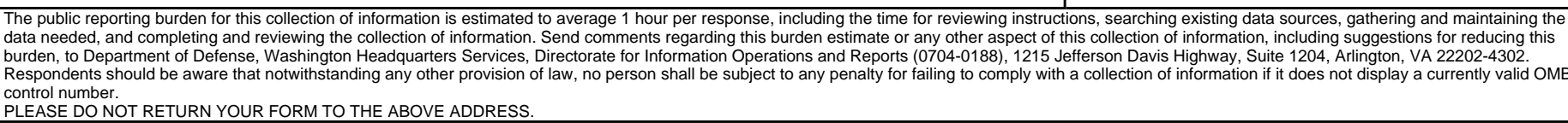 } \\
\hline $\begin{array}{l}\text { 1. REPORT DATE (DD-MM-YYYY) } \\
01-12-2011\end{array}$ & $\begin{array}{l}\text { 2. REPORT TYPE } \\
\text { Technical Memorandum }\end{array}$ & 3. DATES COVERED (From - To) \\
\hline \multirow{3}{*}{\multicolumn{2}{|c|}{$\begin{array}{l}\text { 4. TITLE AND SUBTITLE } \\
\text { Engine Icing Modeling and Simulation (Part 2): Performance Simulation of Engine Rollback } \\
\text { Phenomena }\end{array}$}} & 5a. CONTRACT NUMBER \\
\hline & & 5b. GRANT NUMBER \\
\hline & & 5c. PROGRAM ELEMENT NUMBER \\
\hline \multirow{3}{*}{\multicolumn{2}{|c|}{$\begin{array}{l}\text { 6. AUTHOR(S) } \\
\text { May, Ryan, D.; Guo, Ten-Huei; Veres, Joseph, P.; Jorgenson, Philip, C.E. }\end{array}$}} & 5d. PROJECT NUMBER \\
\hline & & 5e. TASK NUMBER \\
\hline & & $\begin{array}{l}\text { 5f. WORK UNIT NUMBER } \\
\text { WBS 284848.02.06.03.02 }\end{array}$ \\
\hline \multicolumn{2}{|c|}{$\begin{array}{l}\text { 7. PERFORMING ORGANIZATION NAME(S) AND ADDRESS(ES) } \\
\text { National Aeronautics and Space Administration } \\
\text { John H. Glenn Research Center at Lewis Field } \\
\text { Cleveland, Ohio 44135-3191 }\end{array}$} & $\begin{array}{l}\text { 8. PERFORMING ORGANIZATION } \\
\text { REPORT NUMBER } \\
\text { E-17885 }\end{array}$ \\
\hline \multirow{2}{*}{\multicolumn{2}{|c|}{$\begin{array}{l}\text { 9. SPONSORING/MONITORING AGENCY NAME(S) AND ADDRESS(ES) } \\
\text { National Aeronautics and Space Administration } \\
\text { Washington, DC 20546-0001 }\end{array}$}} & $\begin{array}{l}\text { 10. SPONSORING/MONITOR'S } \\
\text { ACRONYM(S) } \\
\text { NASA }\end{array}$ \\
\hline & & $\begin{array}{l}\text { 11. SPONSORING/MONITORING } \\
\text { REPORT NUMBER } \\
\text { NASA/TM-2011-217200 }\end{array}$ \\
\hline \multicolumn{3}{|c|}{$\begin{array}{l}\text { 12. DISTRIBUTION/AVAILABILITY STATEMENT } \\
\text { Unclassified-Unlimited } \\
\text { Subject Category: } 07 \\
\text { Available electronically at http://www.sti.nasa.gov } \\
\text { This publication is available from the NASA Center for AeroSpace Information, 443-757-5802 }\end{array}$} \\
\hline
\end{tabular}

\section{ABSTRACT}

Ice buildup in the compressor section of a commercial aircraft gas turbine engine can cause a number of engine failures. One of these failure modes is known as engine rollback: an uncommanded decrease in thrust accompanied by a decrease in fan speed and an increase in turbine temperature. This paper describes the development of a model which simulates the system level impact of engine icing using the Commercial Modular Aero-Propulsion System Simulation 40k (C-MAPSS40k). When an ice blockage is added to C-MAPSS40k, the control system responds in a manner similar to that of an actual engine, and, in cases with severe blockage, an engine rollback is observed. Using this capability to simulate engine rollback, a proof-of-concept detection scheme is developed and tested using only typical engine sensors. This paper concludes that the engine control system's limit protection is the proximate cause of iced engine rollback and that the controller can detect the buildup of ice particles in the compressor section. This work serves as a feasibility study for continued research into the detection and mitigation of engine rollback using the propulsion control system.

15. SUBJECT TERMS

Ice formation; Commercial aircraft; Propulsion system; Engine rollback; Engine control

\begin{tabular}{|c|c|c|c|c|c|}
\hline \multicolumn{3}{|c|}{ 16. SECURITY CLASSIFICATION OF: } & \multirow{2}{*}{$\begin{array}{l}\text { 17. LIMITATION OF } \\
\text { ABSTRACT } \\
\text { UU }\end{array}$} & \multirow{2}{*}{$\begin{array}{l}\text { 18. NUMBER } \\
\text { OF } \\
\text { PAGES } \\
14\end{array}$} & \multirow{2}{*}{$\begin{array}{l}\text { 19a. NAME OF RESPONSIBLE PERSON } \\
\text { STI Help Desk (email:help@sti.nasa.gov) } \\
\text { 19b. TELEPHONE NUMBER (include area code) } \\
\text { 443-757-5802 }\end{array}$} \\
\hline $\begin{array}{l}\text { a. REPORT } \\
U\end{array}$ & $\begin{array}{l}\text { b. ABSTRACT } \\
\mathrm{U}\end{array}$ & $\begin{array}{l}\text { c. THIS } \\
\text { PAGE } \\
\text { U }\end{array}$ & & & \\
\hline
\end{tabular}



